\title{
Near-field tsunami forecast system based on near real-time seismic moment tensor estimation in the regions of Indonesia, the Philippines, and Chile
}

\author{
Daisuke Inazu ${ }^{1,2^{*}}$, Nelson Pulido², Eiichi Fukuyama ${ }^{2}$, Tatsuhiko Saito ${ }^{2}$, Jouji Senda ${ }^{2}$ and Hiroyuki Kumagai ${ }^{3}$
}

\begin{abstract}
We have developed a near-field tsunami forecast system based on an automatic centroid moment tensor (CMT) estimation using regional broadband seismic observation networks in the regions of Indonesia, the Philippines, and Chile. The automatic procedure of the CMT estimation has been implemented to estimate tsunamigenic earthquakes. A tsunami propagation simulation model is used for the forecast and hindcast. A rectangular fault model based on the estimated CMT is employed to represent the initial condition of tsunami height. The forecast system considers uncertainties due to two possible fault planes and two possible scaling laws and thus shows four possible scenarios with these associated uncertainties for each estimated CMT. The system requires approximately 15 min to estimate the CMT after the occurrence of an earthquake and approximately another $15 \mathrm{~min}$ to make the tsunami forecast results including the maximum tsunami height and its arrival time at the epicentral region and near-field coasts available. The retrospectively forecasted tsunamis were evaluated by the deep-sea pressure and tide gauge observations, for the past eight tsunamis $\left(M_{w}\right.$ 7.5-8.6) that occurred throughout the regional seismic networks. The forecasts ranged from half to double the amplitudes of the deep-sea pressure observations and ranged mostly within the same order of magnitude as the maximum heights of the tide gauge observations. It was found that the forecast uncertainties increased for greater earthquakes (e.g., $M_{w}>8$ ) because the tsunami source was no longer approximated as a point source for such earthquakes. The forecast results for the coasts nearest to the epicenter should be carefully used because the coasts often experience the highest tsunamis with the shortest arrival time (e.g., <30 min).
\end{abstract}

Keywords: Tsunami forecast, Seismic centroid moment tensor, Forecast accuracy, Forecast uncertainty

\section{Introduction}

Great earthquakes with moment magnitudes $\left(M_{\mathrm{w}}\right)$ greater than about 8 have often generated disastrous tsunamis with many casualties (ITIC 2015). In particular, the 2004 Sumatra $\left(M_{\mathrm{w}} 9.1\right)$ and 2011 Tohoku $\left(M_{\mathrm{w}} 9.0\right)$ tsunamis were extremely disastrous and caused about 200,000 and 20,000 casualties, respectively (e.g., Satake 2014). Practical tsunami early warning systems are necessary for mitigating disasters caused by such great tsunamis.

\footnotetext{
*Correspondence: inazud@oa.u-tokyo.ac.jp

1 UTokyo Ocean Alliance, The University of Tokyo, 7-3-1 Hongo, Bunkyo, Tokyo 113-0033, Japan

Full list of author information is available at the end of the article
}

Seismic waves, crustal deformation, and tsunamis (sea level) are continuously monitored, and these data are mostly available in real time. Seismic waves are primarily observed by onshore seismometers worldwide. Crustal deformations are observed by the global positioning system/global navigation satellite system (GPS/GNSS). Coastal tsunamis are observed at tide gauge stations, and offshore tsunamis are monitored by ocean-bottom pressure gauges (e.g., Rabinovich and Eblé 2015) and GPS sea-surface buoys (e.g., Kawai et al. 2013).

For reliable tsunami warnings, fast-traveling seismic wave data are used to evaluate the sizes of earthquakes and tsunamis, and, if available, offshore tsunami data are then used to reliably evaluate the actual tsunami size 
before tsunami arrival at the coast. Also, onshore coseismic crustal deformation data (GPS/GNSS) with high sampling (e.g., $1 \mathrm{~Hz}$ ) can quickly constrain near-field tsunamigenic earthquake sources as presented in recent studies (e.g., Melgar et al. 2013; Tsushima and Ohta 2014).

Rapid earthquake source estimation systems based on real-time seismic observations have been developed and operated (e.g., Okada et al. 2004; Ekström et al. 2012; Duputel et al. 2012b). Earthquake source estimation is essential for the quickest issuing of tsunami warnings and forecasts. The simplest method is to search for a possible scenario in a pre-computed tsunami simulation database according to the estimated earthquake magnitude with its location (e.g., Tatehata 1997; Kamigaichi 2009; Lauterjung et al. 2010; Igarashi et al. 2015). There are various types of earthquake magnitudes, such as local magnitude, body-wave magnitude, surface-wave magnitude, and $M_{\mathrm{w}}$ (e.g., Utsu 2001; Shearer 2009). It is important to use the $M_{\mathrm{w}}$ for tsunami warning because the $M_{\mathrm{w}}$ reflects the fault displacement that is directly related to the tsunami generation. Using the moment tensor with $M_{\mathrm{w}}$ can facilitate more reliable tsunami forecasts (e.g., Reymond et al. 2012; Gusman and Tanioka 2014). Tsunami forecast systems based on the estimated centroid moment tensor (CMT) have been installed by the Pacific Tsunami Warning Center (PTWC) (e.g., Wang et al. 2012; PTWC/ ITIC 2014) and the French Polynesian Tsunami Warning Center (CPPT: Centre Polynésien de Prévention des Tsunamis) (e.g., Clément and Reymond 2015; Jamelot and Reymond 2015).

Using real-time offshore tsunami observations probably facilitates more reliable forecasts than using observations from seismic data alone. Tsunami forecast systems that use offshore tsunami observations have been developed by the National Oceanic and Atmospheric Administration (NOAA) (e.g., Tang et al. 2009, 2012) and the Japan Meteorological Agency (JMA) (e.g., Tsushima et al. 2009, 2011, 2012). Recently, other reliable forecast methods that use dense offshore observation networks have been also suggested (Baba et al. 2014; Maeda et al. 2015). Forecast systems using tsunami observation can be reliable but require substantially longer times, because it typically takes tens of minutes for a tsunami to reach to the nearest offshore stations (e.g., Tang et al. 2012; Wei et al. 2013). For rapid and reliable forecasts, some studies have suggested that the initial tsunami height based on a finite-fault model inferred from seismic and/or geodetic observations is used as an initial guess, and successive offshore tsunami observations can facilitate a more reliable forecast (e.g., Melgar and Bock 2013; Tsushima et al. 2014).
On the other hand, there are many coastal communities for which offshore tsunami observations are not available for use in early warning because observation points are sparse around the target coastal areas (e.g., Rabinovich and Eblé 2015). So the tsunami forecast system based on seismic observation alone still plays an important role for disaster mitigations of coastal communities.

The tsunami forecast systems of PTWC and CPPT primarily use CMTs estimated by teleseismic body-wave inversions. The robust estimations of these CMTs require at least several tens of minutes after the origin time, especially for great earthquakes $\left(M_{\mathrm{w}}>8\right)$ (e.g., Duputel et al. 2011). These tsunami forecast systems require time to estimate the CMT solution and to calculate the tsunami. It is therefore important to reduce the time to estimate CMT and to calculate tsunami for a rapid warning, especially for near-field tsunamis. In order to reduce the CMT estimation time, we prefer to use near-field seismic data, which is available earlier than teleseismic data.

Regional broadband seismic observation networks have been deployed in Indonesia (Ohtaki et al. 2000; Miyakawa et al. 2007; Nakano et al. 2010), the Philippines (Inoue and Solidum 2015; Bonita et al. 2015; Punongbayan et al. 2015), and Chile (Barrientos 2014) (Fig. 1). These observation networks are maintained by the Indonesian Agency for Meteorological, Climatological and Geophysics (BMKG: Badan Meteorologi, Klimatologi, dan Geofisika), the Philippine Institute of Volcanology and Seismology (PHIVOLCS), the University of Chile, and the German Research Centre for Geosciences (GFZ: Deutsches GeoForschungsZentrum). Observed seismic waveform data in Indonesia and the Philippines are obtained in real time by the National Research Institute for Earth Science and Disaster Resilience (NIED), Japan, through the framework of cooperative research projects with the BMKG (Miyakawa et al. 2007) and the PHIVOLCS (Inoue and Solidum 2015). The other data in the observation networks are also received by the NIED through the public servers of the Incorporated Research Institutions for Seismology (IRIS) and the German Geo Research Network (GEOFON: GEOFOrschungsNetz).

Within the framework of an automatic/manual CMT estimation called the source-parameter determinations based on waveform inversion of Fourier Transformed seismograms (SWIFT) system (Nakano et al. 2008, 2010), the NIED has routinely analyzed the observed seismic data and maintained a database of the estimated CMTs of earthquakes that have occurred throughout the regional seismic networks. The time required for the CMT estimation using the near-field regional seismic data is expected to be shorter than that from the teleseismic data inversion. We have recently implemented an automatic CMT 

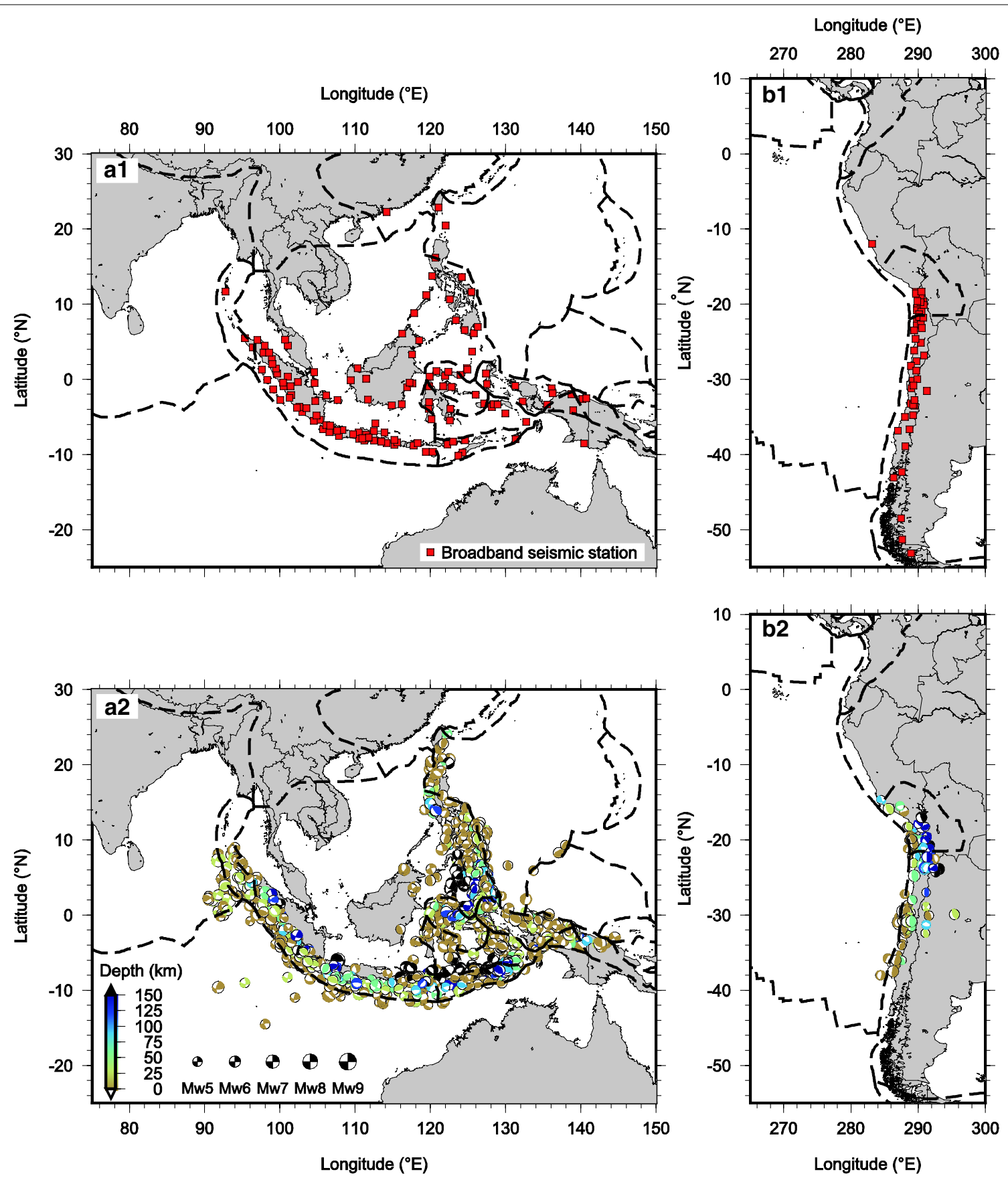

Fig. 1 (Upper) Broadband seismic observation networks, and (lower) estimated CMTs of detected earthquakes by the SWIFT system in the regions of $\mathbf{a}$ Indonesia and the Philippines, and $\mathbf{b}$ Chile. Red squares indicate the broadband seismic stations currently used by SWIFT: 133 stations in $\mathbf{a}$ and 48 stations in b. A total of 1488 CMTs of $M_{w} 4.3-8.6$ throughout Indonesia and the Philippines were obtained from June 25, 2007, to December 31, 2015, and 220 CMTs of $M_{w}$ 4.0-8.2 throughout Chile were obtained from April 24, 2014, to December 31, 2015. Dashed curves indicate plate boundaries derived from Bird (2003)

estimation procedure for large earthquakes $\left(M_{\mathrm{w}}>7\right)$ into the previous SWIFT system (Nakano et al. 2008) and have incorporated a tsunami forecast system based on the estimated CMT. In the present paper, we briefly describe the automatic CMT estimation procedure, then describe the tsunami forecast system, show the forecast accuracy, and discuss its applicability to disaster mitigation. 


\section{SWIFT CMT solution}

To estimate the earthquake source, the NIED collects real-time continuous seismic waveform data from 181 broadband seismic stations in Indonesia, the Philippines, Chile, and adjacent regions (Fig. 1) using the SeisComP3 system (e.g., Olivieri and Clinton 2012). The SeisComP3 system estimates in real time, the origin time, hypocenter, and magnitude of detected earthquakes. The estimation triggers the SWIFT system to automatically calculate CMT and source time function of the detected earthquake (Bonita et al. 2015; Punongbayan et al. 2015). The automatically estimated CMT solutions are checked, manually revised, and listed in a searchable database (www.isn.bosai.go.jp). The total number of estimated CMTs is 1488 in the range of $M_{\mathrm{w}} 4.3-8.6$ around Indonesia and the Philippines from June 25, 2007, to December 31, 2015, and 220 in the range of $M_{\mathrm{w}} 4.0-8.2$ around Chile from April 24, 2014, to December 31, 2015 (Fig. 1).

In particular for large earthquakes $\left(M_{\mathrm{w}}>7\right)$, we have implemented the following automatic procedure in the SWIFT system to obtain a robust CMT solution as rapidly as possible. Once an earthquake is detected, the SWIFT system obtains available seismic waveform data from the SeisComP3 ring buffer and performs a quality check in terms of signal-to-noise ratio, gaps, clipping, and strong acceleration pulses in the waveform data. A list of datasets (east-west, north-south, and up-down components of the waveform data observed at available seismic stations) that has successfully passed the check is compiled as the accepted data. The SeisComP3 estimation of the origin time, hypocenter, and magnitude is used as an initial guess for the CMT search. For $M_{\mathrm{w}}<7$ earthquakes, the CMT search is performed using all of the accepted data. The waveform data used are filtered for a passband of 50-100 s. For $7<M_{\mathrm{w}}<8$ earthquakes, the CMT search is performed using accepted data having epicentral distances of $500-1500 \mathrm{~km}$, with a passband of 50-100 s. For $M_{\mathrm{w}}>8$ earthquakes, the CMT search is performed using accepted data having epicentral distances of $1000-1500 \mathrm{~km}$, with a passband of 50-200 s. The selection criteria of the waveform data with the epicentral distances longer than $1000 \mathrm{~km}$ and the passband of 50-200 s for $M_{\mathrm{w}}>8$ earthquakes are applied to guarantee the point-source assumption for the CMT estimation (Fukuyama and Dreger 2000) and to prevent the use of pulse data that are clipped or too strong, which may worsen the CMT estimate.

Several tsunamigenic earthquakes $\left(M_{\mathrm{w}}\right.$ 7.5-8.6) have been observed by the SWIFT seismic networks (Fig. 2 and Table 1). With the automatic data procedure described above, we have confirmed that the CMTs of these tsunamigenic earthquakes could have been successfully estimated $\sim 15 \mathrm{~min}$ after the earthquake occurrence.
The retrospectively estimated CMTs of the tsunamigenic earthquakes are compared to the CMTs derived from teleseismic data in the catalogs of the Global CMT (GCMT) Project (Ekström et al. 2012) and the USGS W-phase inversion (Duputel et al. 2012b) (Fig. 3). Our SWIFT CMT solutions are in good agreement with the GCMT and USGS solutions except for the Mentawai tsunami earthquake that occurred on October 25, 2010 (e.g., Satake et al. 2013; Yue et al. 2014).

\section{Tsunami forecast using SWIFT CMT}

We have developed a successive automatic tsunami calculation system starting from the automatically estimated CMT using the procedure mentioned in the previous section. The tsunami calculation system is used for both forecast and hindcast. The tsunami calculation system (hereafter the SWIFT TSUNAMI system) is described in this section.

When the estimated SWIFT CMT satisfies the conditions $M_{\mathrm{w}}>5.5$ and a focal depth shallower than $100 \mathrm{~km}$, the SWIFT TSUNAMI system decides that the detected earthquake is possibly tsunamigenic and performs the following analysis. The tsunami forecast results can be available approximately $30 \mathrm{~min}$ after the occurrence of a significant earthquake (i.e., $~ 15$ min to obtain the CMT and $\sim 15 \mathrm{~min}$ for the tsunami calculation).

The initial condition of the tsunami simulation is based on a rectangular fault model with a uniform slip. The estimated CMT gives the strike, dip, and rake of the earthquake source with its centroid location (longitude, latitude, and focal depth). In addition, when the length, width, and slip amount of the finite rectangular fault are given, the seafloor deformation is calculated using the Okada's formula (Okada 1985) with assuming a homogeneous half-space. The center of the rectangular fault is placed at the centroid location. (i) The vertical component of the seafloor deformation due to the faulting primarily determines the seafloor vertical displacement. (ii) A product of the horizontal component and the seafloor gradient at the source region yields an additional seafloor vertical displacement (e.g., Tanioka and Satake 1996). (iii) The tsunami height at the sea surface arises from the seafloor vertical displacement without short-wavelength components. The short-wavelength seafloor vertical displacement is damped by considering a low-pass filtering effect from a local (here $0.5 \mathrm{deg}$ by $0.5 \mathrm{deg}$ ) ocean depth (e.g., Saito and Furumura 2009). We use the tsunami height considering (i), (ii), and (iii) as the initial condition of the tsunami simulation. The seawater velocity is assumed to be zero for the initial condition (Saito 2013). The rise time of the faulting is assumed to be zero.

A single CMT solution involves ambiguity and uncertainty of the parameters used in the rectangular fault, 


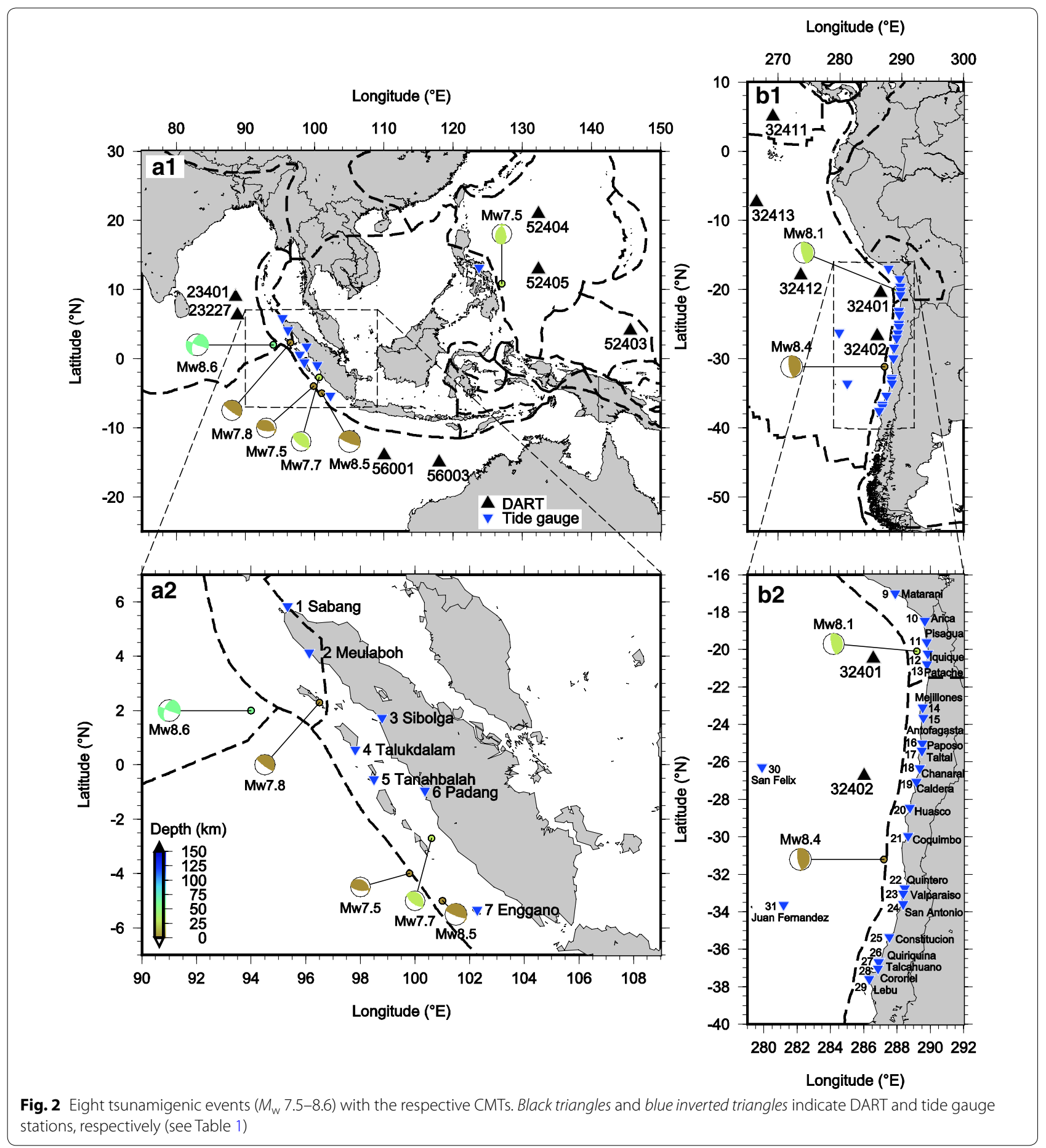

because of the fault plane selection (i.e., double couple) and the finite-fault geometry. Two fault planes are possible because of the double couple. The length, width, and slip amount of the finite fault can be obtained using a certain empirical scaling law. There are various types of proposed scaling laws. The choice of scaling law involves uncertainty for representing the finite faulting. Here, we use two scaling laws. The scaling law proposed by Utsu (2001) gives a relatively small rupture area for a certain $M_{\mathrm{w}}$, which is represented as follows:

$$
D / L=5 \times 10^{-5},
$$




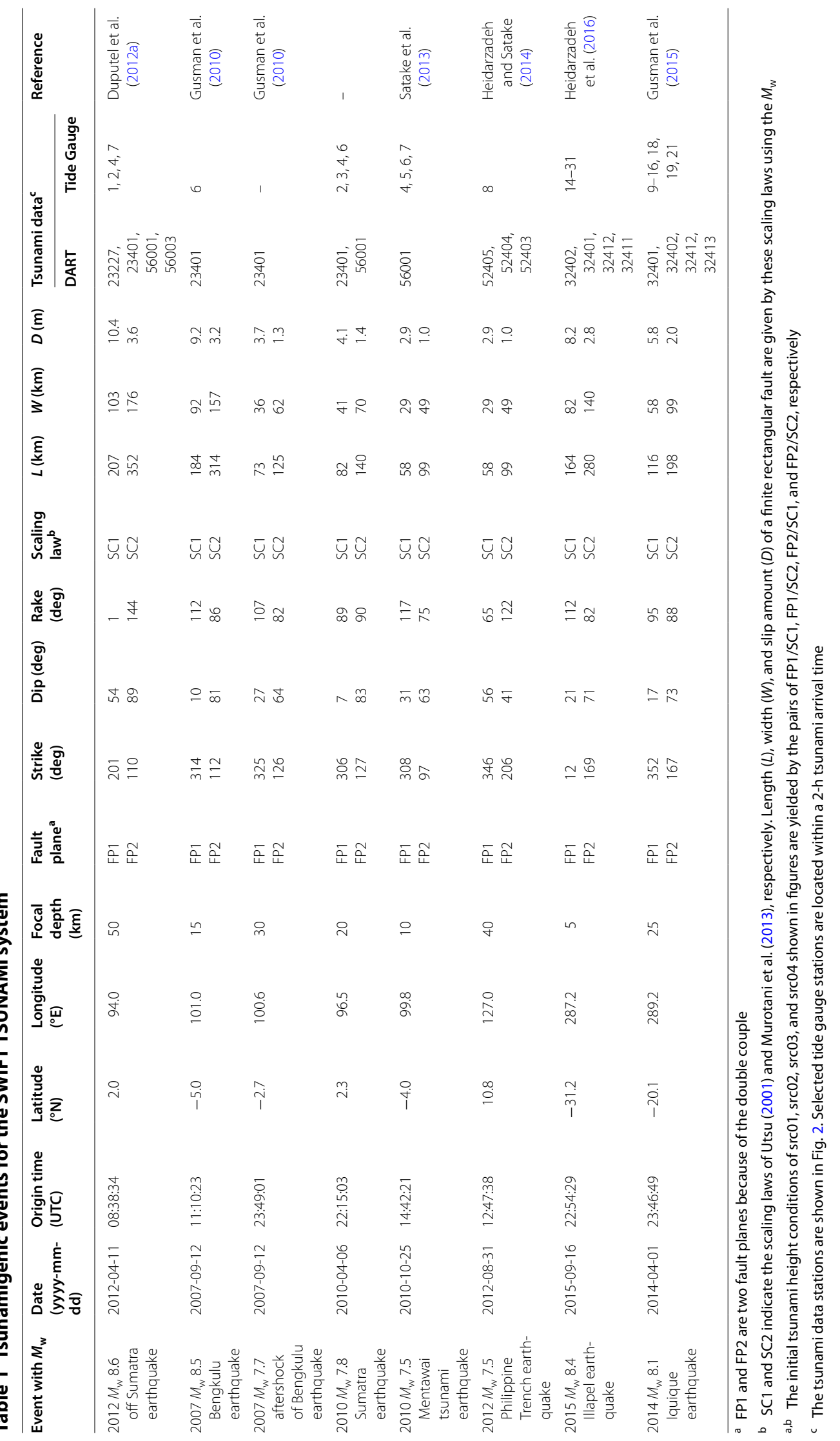




$$
L / W=2 .
$$

In contrast, the scaling law proposed by Murotani et al. (2013) gives a relatively large rupture area:

$$
\begin{aligned}
& L W=1.34 \times 10^{-10} M_{0}^{2 / 3}\left(\mathrm{~km}^{2}\right), \\
& D=1.66 \times 10^{-7} M_{0}^{1 / 3}(\mathrm{~m}) .
\end{aligned}
$$

Equation (2) is also applied for the scaling law proposed by Murotani et al. (2013). Here, $L, W$, and $D$ are the length, width, and slip amount of the finite faulting, respectively. $M_{0}$ is the seismic moment in Newton meters:

$$
M_{0}=\mu L W D .
$$

Here, $\mu(=45 \mathrm{GPa})$ is the rigidity coefficient. $M_{0}$ is related to $M_{\mathrm{w}}$ through a fundamental relationship (Hanks and Kanamori 1979):

$$
M_{\mathrm{w}}=\left(\log M_{0}-9.1\right) / 1.5 .
$$

$M_{0}$ is given according to the CMT solution. For the Utsu's scaling law, $D$ is estimated using Eqs. (1), (2), and (5). $L$ and $W$ are then estimated using Eqs. (1) and (2). For the scaling law of Murotani et al. (2013), $D$ is estimated using Eq. (4). $L$ and $W$ are then estimated using Eqs. (3) and (2). For the respective scaling laws, the maximum $W$ is limited to $200 \mathrm{~km}$, considering the depth range of typical megathrust zones (e.g., Oleskevich et al. 1999). When $L$ becomes $>400 \mathrm{~km}, W$ is fixed at $200 \mathrm{~km}$. In this case, it is allowed for $L / W>2$ while maintaining $L W$ (rupture area) constant. The focal depth can be modified to be deeper than the centroid location so that the shallowest tip of the faulting is limited to $0.5 \mathrm{~km}$.

Four scenarios constructed from the two fault planes and the above two scaling laws are considered to be the initial tsunami heights in the present study. Figure 4 shows an example of the great $M_{\mathrm{w}} 8.6$ off Sumatra strikeslip earthquake that occurred on April 11, 2012 (Fig. 2) (e.g., Duputel et al. 2012a). The separate contributions of (i), (ii), and (iii) to the initial condition (Fig. 4a) are also shown in Fig. 5.

The tsunami simulation is carried out using the initial condition. Here, the simulation is based on a linear longwave model (Inazu and Saito 2013, 2016). The horizontal resolution is 5 arcmin. The ETOPO1 dataset (Amante and Eakins 2009) is used to configure the bathymetry.

During the simulation, snapshots of the tsunami height field and time series at selected stations, and sequential animations of these snapshots are made (Fig. 6). The maximum tsunami height distribution together with its arrival time is figured for each scenario (Fig. 7). The maximum height with its arrival time along the coast is quite important for warning and damage evaluation in coastal communities. The alongshore result is also shown (Fig. 8). The results shown in Figs. 4 through 8 are obtained for each detected tsunamigenic earthquake $\left(M_{\mathrm{w}}>5.5\right)$. For comparison, Fig. 9 shows the results for a small tsunami due to the $M_{\mathrm{w}} 7.5$ Philippine Trench earthquake that occurred on August 31, 2012 (Fig. 2) (e.g., Ye et al. 2012; Heidarzadeh and Satake 2014).

As mentioned above, substantial time is required after the occurrence of a significant earthquake to estimate the robust CMT ( 15 $\mathrm{min})$ and the tsunami height with the arrival time (another $\sim 15 \mathrm{~min}$ ). The results along the coast (Figs. 7, 8, 9) for which the maximum height arrival time is less than 30 min cannot be used for the purpose of forecasting, but are useful for hindcasting and postdisaster evaluations.

\section{Forecast accuracy and uncertainty}

Tsunami forecast systems similar to the SWIFT TSUNAMI system have been also developed by PTWC and CPPT. The PTWC system has shown forecast results with successively updated CMT solutions (Wang et al. 2012). The CPPT study has shown forecast uncertainties with respect to CMTs derived from different research institutions (Jamelot and Reymond 2015). We show the forecast uncertainties due to the fault plane selection, the scaling laws used, and other possible factors, especially for greater earthquakes and tsunamis.

We evaluate the forecast accuracy of the SWIFT TSUNAMI system. Eight large earthquakes $\left(M_{\mathrm{w}} 7.5-8.6\right)$ from 2007 to 2015 were tsunamigenic as detected by the ocean-bottom pressure observations of the Deep-ocean Assessment and Reporting of Tsunamis (DART) system (e.g., Mungov et al. 2013) (Fig. 2). The retrospective forecasts of the eight events based on the SWIFT CMTs are first compared to the DART observations and are then compared to the coastal tide gauge observations.

Here, we define the total amplitude as the local maximum minus the local minimum during the leading wave. The total amplitude of the leading wave of the DART observations is used as a measure of the forecast accuracy (Fig. 10). The forecasts for the four scenarios roughly range from half to double the observational amplitudes (Fig. 11). We also evaluate the forecast accuracy in terms of the tide gauge observations. The maximum height during each tsunami event is used for the comparison (Figs. 7, 8, 9). The maximum tsunami height at the tide gauge station is compared to that calculated at the coastal grid of the tide gauge location. The forecasts of the four scenarios for the maximum tsunami height at the coast at most range from $1 / 5$ to 5 times the observations (Fig. 12). 


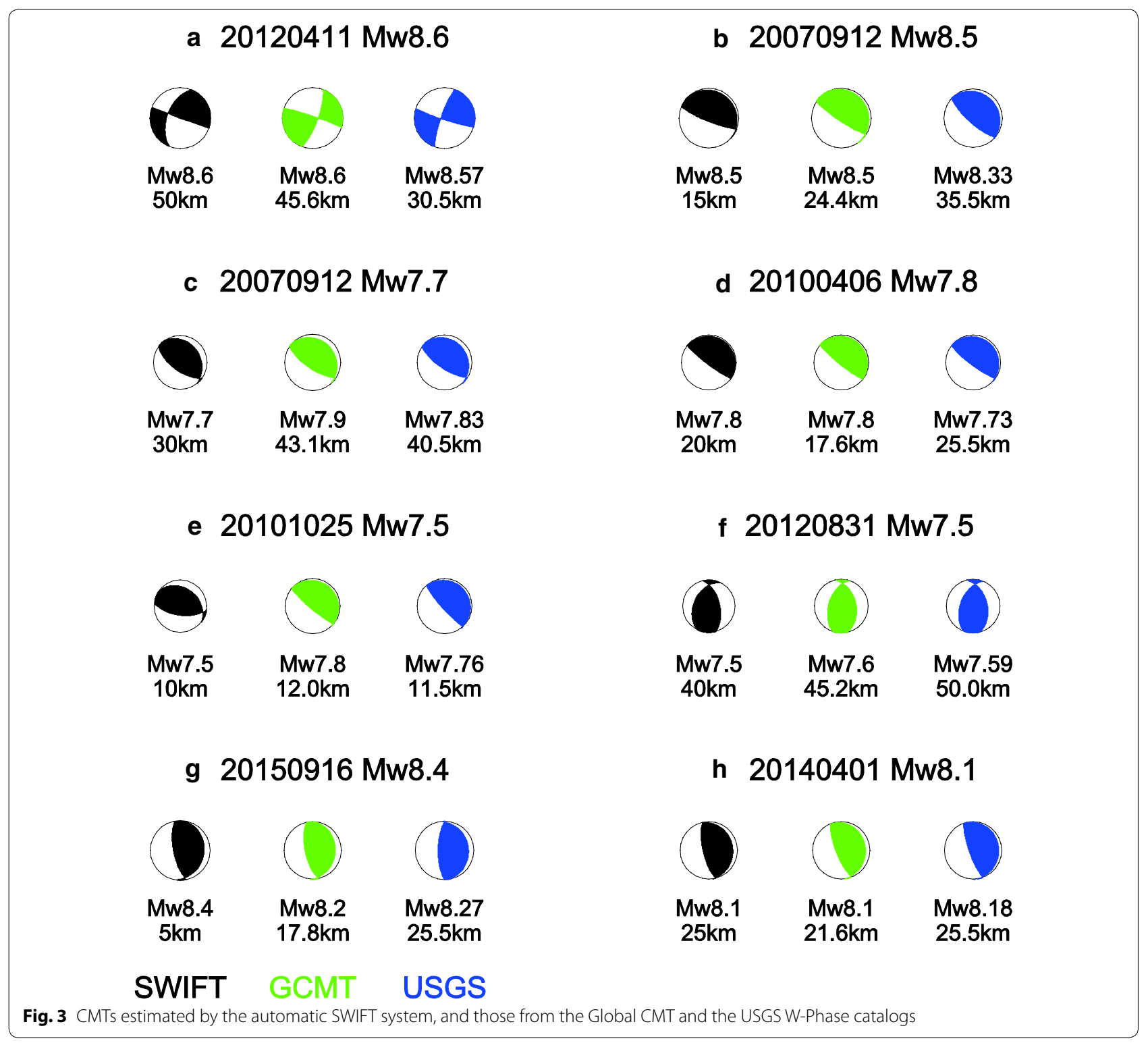

The tsunami size of the 2010 Mentawai tsunami earthquake was notably underestimated by the SWIFT TSUNAMI system (Figs. 11, 12). The Mentawai tsunami earthquake was estimated as $M_{\mathrm{w}} 7.5$ by the SWIFT estimation, which is significantly smaller than $M_{\mathrm{w}} \sim 7.8$ as derived from the GCMT and USGS solutions (Fig. 3e). If we changed the $M_{\mathrm{w}}$ to 7.8 in the SWIFT solution, we confirmed that the underestimation was suitably compensated. Although the automatic SWIFT CMT estimation procedure proposed in the present study is intended for large earthquakes $\left(M_{\mathrm{w}}>7\right)$, the procedure may still have difficulty in reasonably evaluating the size of tsunami earthquakes. Improvements especially for reliable
$M_{\mathrm{w}}$ estimation will be necessary for the proposed procedure to work for tsunami earthquakes. With the exception of the Mentawai tsunami earthquake, the forecasts range mostly within the same order of magnitude as the maximum heights of the tide gauge observations.

We also find that the forecast differences (standard deviation) between the four scenarios increase for the larger events and decrease for the smaller events (Figs. 11b, 12b). The dependence of the forecast differences on $M_{\mathrm{w}}$ is recognized in Figs. 7 through 10. For small $M_{\mathrm{w}}$ events (e.g., $M_{\mathrm{w}}$ 7.5), the differences in the fault plane selection and in the scaling laws used result in relatively small differences in the initial tsunami height 


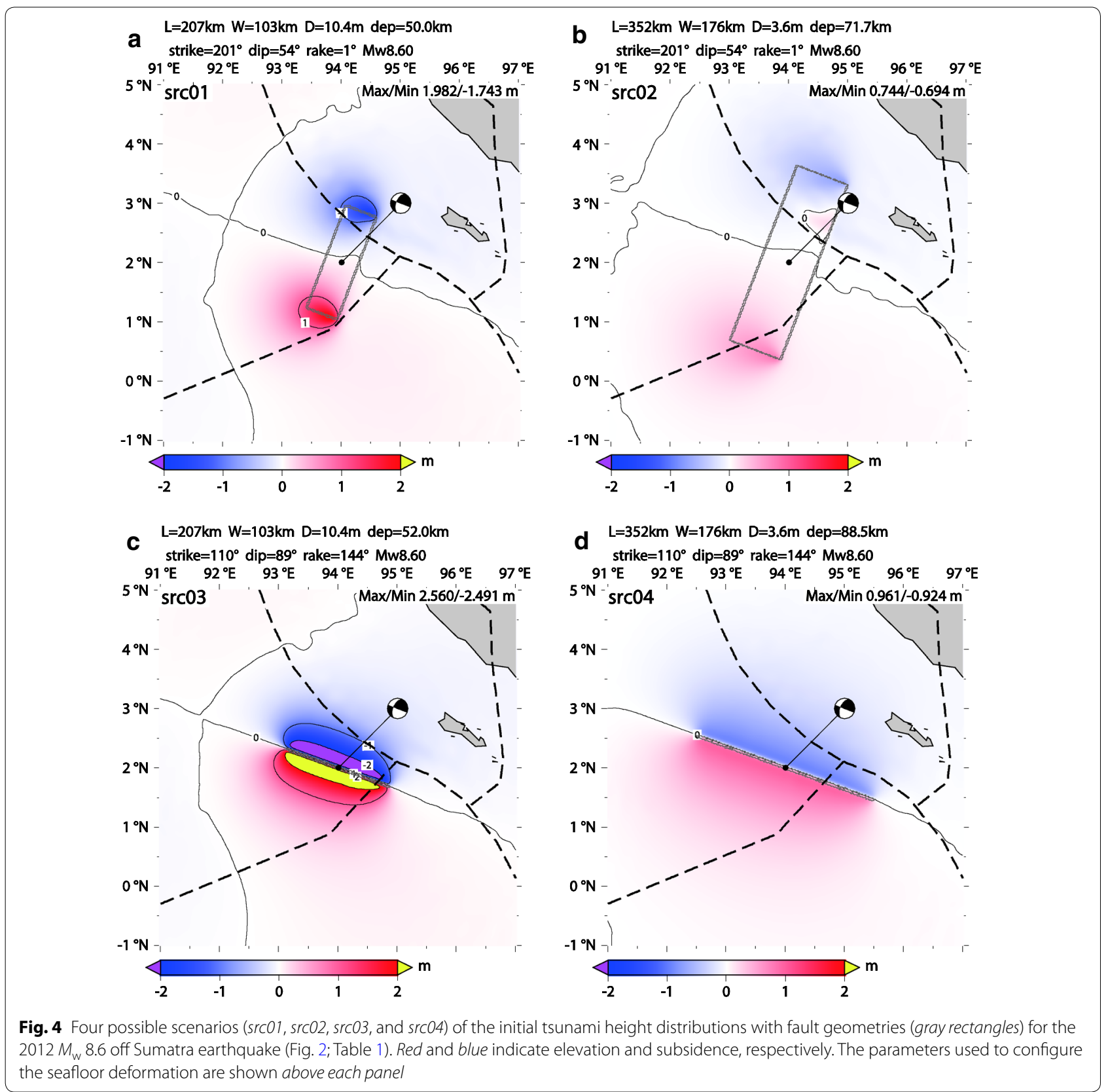

condition, indicating that the tsunami source is approximated as a point source and result in small differences in the forecasts (Figs. 9 and 10b). For the larger $M_{\mathrm{w}}$ events (e.g., $M_{\mathrm{w}}>8.0$ ), however, the tsunami sources significantly deviate from the point source, and the differences in the finite-fault size cause relatively large variations in the forecasts (Figs. 7, 8, 10a). It is worth noting that the dependence of the forecast uncertainty on $M_{\mathrm{w}}$ indicates that accurate and robust tsunami forecasting becomes more difficult for larger earthquakes.

\section{Discussion for future perspectives}

In this section, we discuss the future perspectives of the SWIFT TSUNAMI system with respect to (1) accuracy, (2) uncertainty, and (3) practical applicability.

(1) Compiling accurate and reliable bathymetry data with a higher spatial-grid resolution for the simulation is essential to accurate tsunami forecasting at the target regions. Local but high-accuracy multibeam survey data are preferably incorporated 


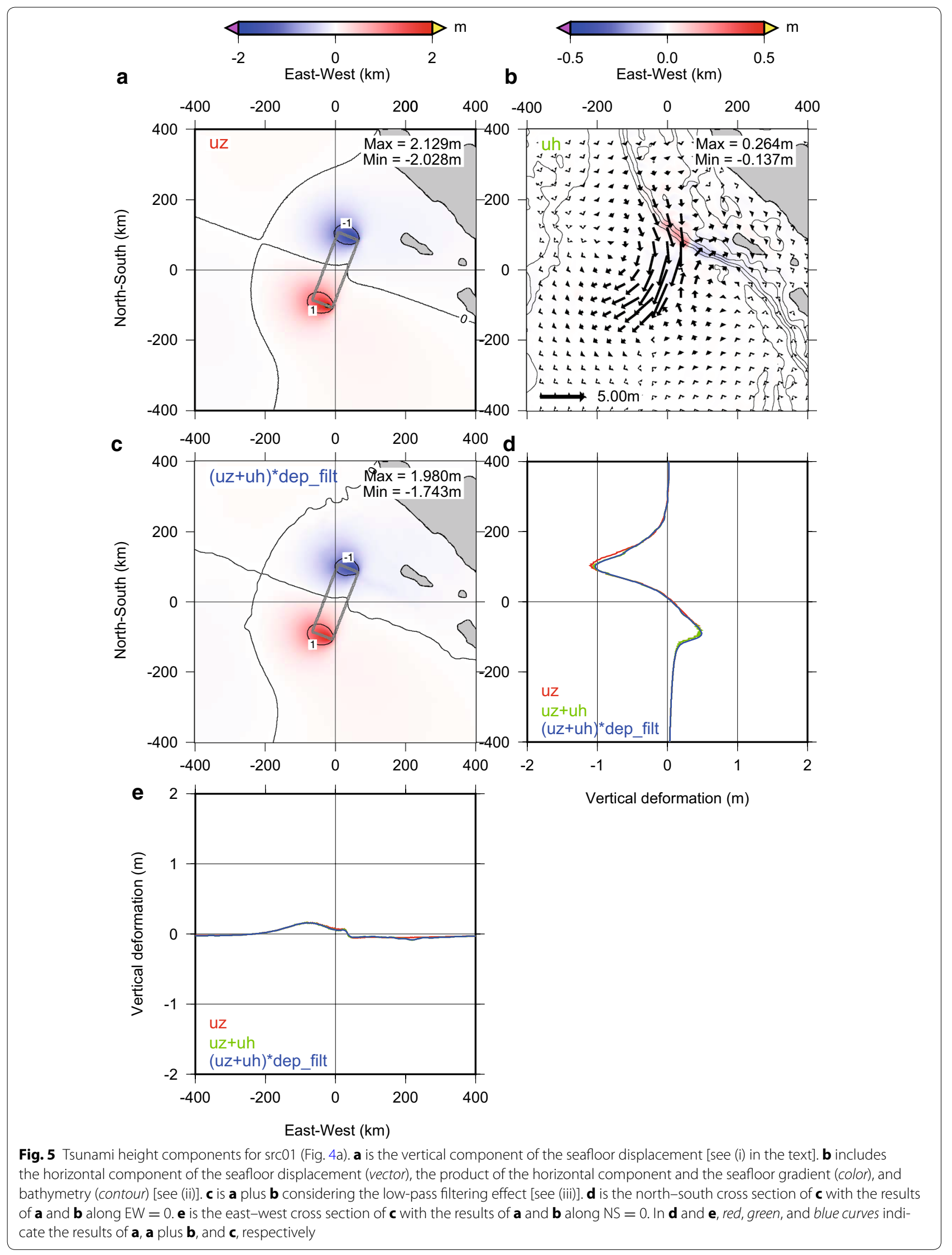




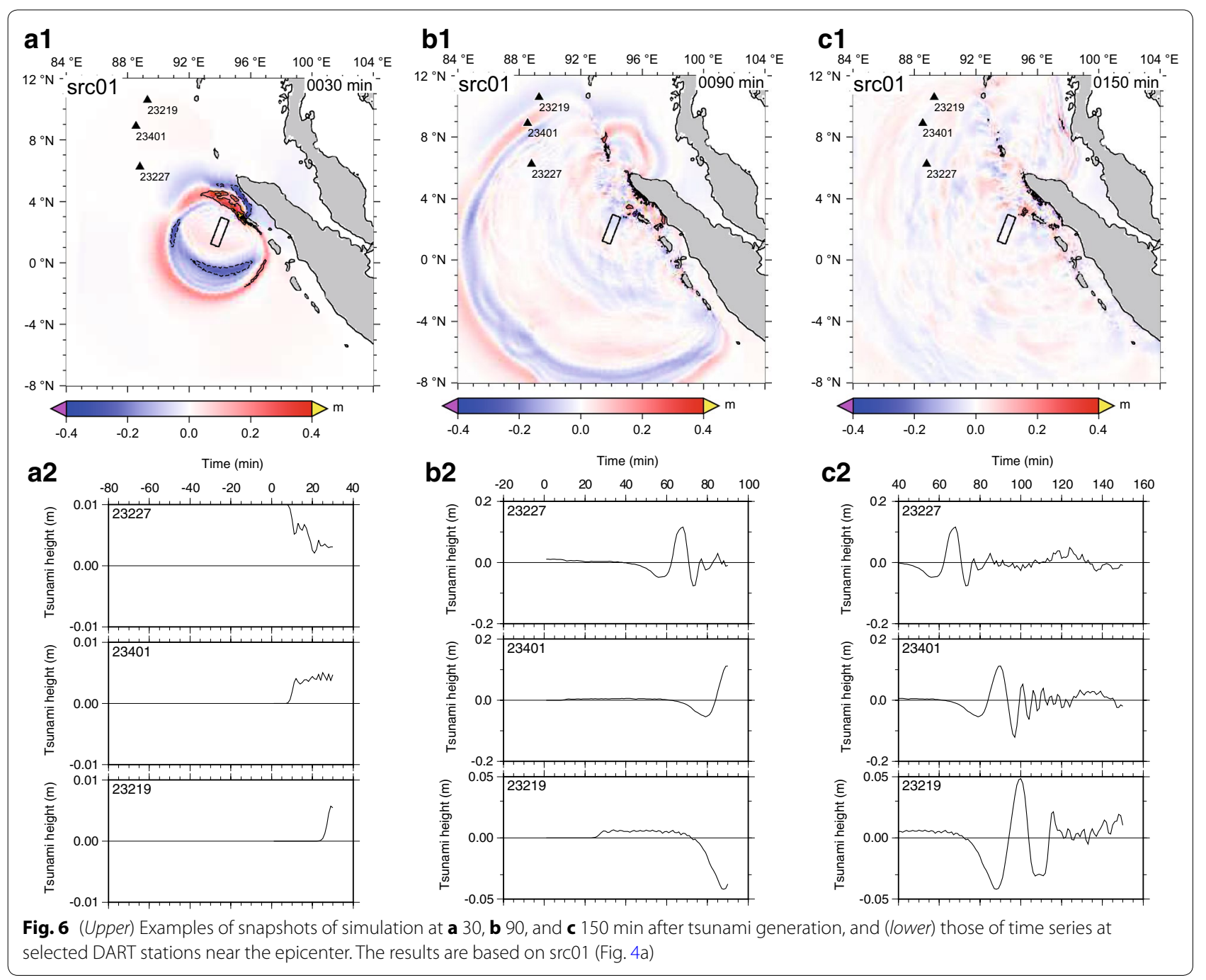

into the fundamental ETOPO or GEBCO datasets (e.g., Satake et al. 2013; Eakins and Grothe 2014; Weatherall et al. 2015; Calisto et al. 2015). In the present study, we used the framework of a global tsunami simulation (Inazu and Saito 2013, 2016), but the simulations will be suitably carried out in the regional domain in the vicinity of the SWIFT seismic networks in Indonesia/the Philippines, and Chile, in order to efficiently reduce the computation time with the high grid resolution. Tsunami simulation modeling that includes nonlinear advection with inundation, seafloor friction, and wave dispersion may be also necessary for accurate forecast although the comprehensive modeling requires additional computational time (e.g., Saito et al. 2014; Miyoshi et al. 2015; Baba et al. 2015). A calculated map of the inundation area with height will be required for the forecast products as well. This will be possible using latest supercomputing systems that have shown abilities to facilitate real-time tsunami forecasts with suitable inundation by high-resolution (< $10 \mathrm{~m}$ ) simulation (Oishi et al. 2015; Musa et al. 2015; Baba et al. 2016).

(2) We discuss in detail the uncertainties of the tsunami forecasting based on seismic data alone, especially for great earthquakes. The real-time inferred $M_{\mathrm{w}}$ ordinarily involves an uncertainty of \pm 0.2 (e.g., Nakano et al. 2010; Jamelot and Reymond 2015; Bonita et al. 2015) and may be significantly underestimated. One striking example was that the JMA issued the earthquake magnitude of 7.9 for the $2011 M_{\mathrm{w}} 9.0$ Tohoku earthquake (e.g., Ozaki 2011, 2012). The reliable $M_{\mathrm{w}}$ estimate is essential. When the estimated $M_{\mathrm{w}}$ is reliable, the scaling law used is 

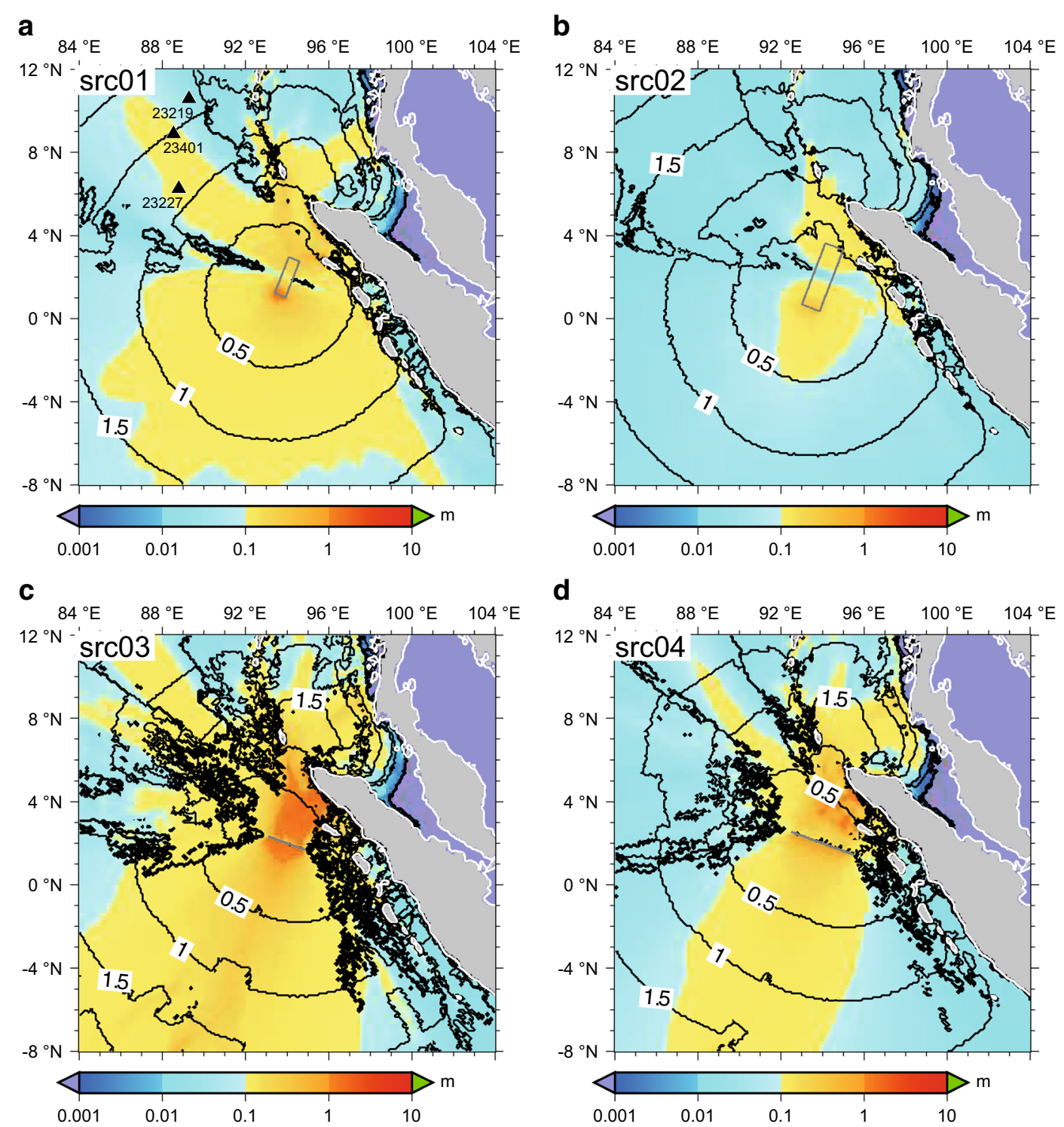

Fig. 7 Distributions of maximum tsunami height (color, m) and its arrival time (contour, h) for the four scenarios (Fig. 4)

secondarily important. The 2004 Sumatra and 2010 Tohoku earthquakes involved comparable $M_{\mathrm{w}}$ of 9.1 and 9.0, respectively. The tsunami source extended $900 \mathrm{~km}$ long for the 2004 Sumatra event (e.g., Fujii and Satake 2007), which can be suitably represented by a large-rupture-area scaling law (e.g., Murotani et al. 2013). The tsunami source for the 2011 Tohoku event, however, extended $300 \mathrm{~km}$ long at most (e.g., Gusman and Tanioka 2014), which should be represented by a small-rupture-area scaling law (e.g., Utsu 2001). The difference in the scaling law used for tsunami calculation becomes more notable for greater earthquakes. In addition, as expected for tsunami earthquakes and great-earthquake-induced seafloor failures, the observed tsunami size may be notably larger than that estimated based on the seismic data alone, especially for greater earthquakes (e.g., Tanioka and Seno 2001; Watts et al. 2005; Kawamura et al. 2014). When offshore tsunami observation data (e.g., DART and GPS buoy) are available in near real time, we may be able to reduce the uncertainty and select probable scenarios (e.g., Melgar and Bock 2013; Tsushima et al. 2014).

(3) The SWIFT TSUNAMI system has been developed for tsunami disaster mitigation, especially for great tsunamis. We discuss the forecast results from the 


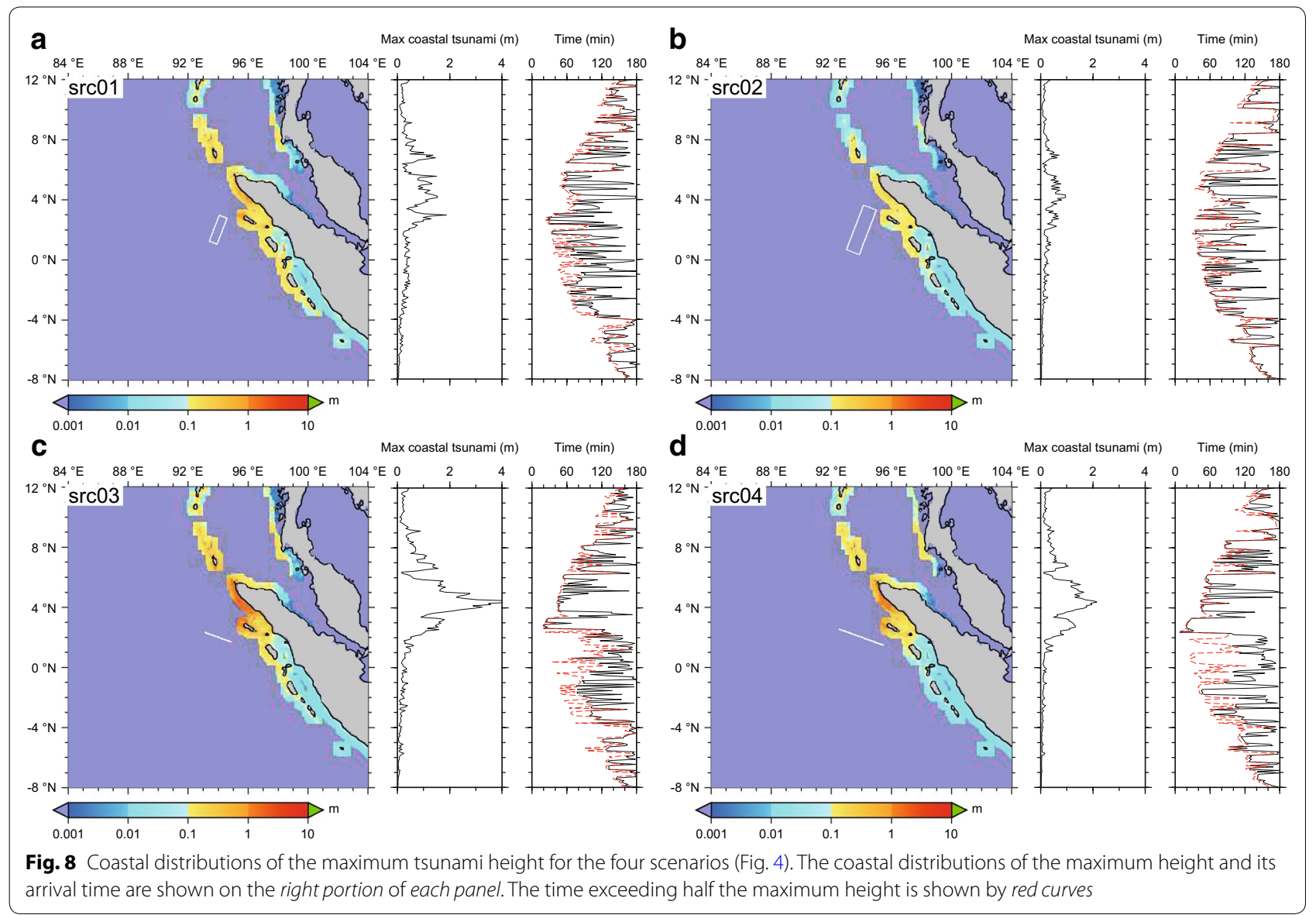

viewpoint of users. Users should consider the worstcase scenario from the forecasts for early warning and remember that the forecast may underestimate the tsunami size in cases of tsunami earthquakes and great-earthquake-induced seafloor failures. Because we need 30 min from the occurrence of the earthquake to obtain the SWIFT tsunami forecast, we cannot use the estimated results for the forecast at coasts in the vicinity of the epicenter within a 30-min arrival time (Figs. 8, 9). Unfortunately, however, near-field coasts with a short arrival time experience the highest wave in many tsunami events. In addition, seismic waveform analysis and obtaining a reliable CMT solution require substantial time of 10-20 min even though the tsunami calculation time may be reduced. Users should recognize whether their target regions can receive a reliable forecast before or just after a significant earthquake occurrence. The forecast results at the nearest coasts may not be used before the disaster, but will be useful for post-disaster damage evaluations and remediation activities.

\section{Summary}

We have described the automatic procedure of the CMT estimation of the SWIFT system for great earthquakes $\left(M_{\mathrm{w}}>7\right)$, and the associated tsunami forecast/hindcast system, in the regions of Indonesia, the Philippines, and Chile. The current system requires $\sim 15 \mathrm{~min}$ to estimate the CMT of the detected earthquake and another $\sim 15$ min for the tsunami calculation; forecast results are available at www.isn.bosai.go.jp.

The retrospectively estimated SWIFT CMT solutions have shown good agreement with the GCMT and USGS solutions for the past seven tsunamigenic earthquakes $\left(M_{\mathrm{w}} 7.5-8.6\right)$ that occurred throughout the SWIFT seismic networks, excluding the 2010 Mentawai tsunami earthquake. The estimated $M_{\mathrm{w}}$ of the SWIFT CMT for this tsunami earthquake was notably underestimated compared to the GCMT and USGS solutions. The calculated tsunami height derived from the SWIFT CMT was also underestimated compared to the offshore and coastal tsunami observations. The current automatic SWIFT CMT estimation procedure may still have difficulty in estimating the size of tsunami earthquakes accurately. 

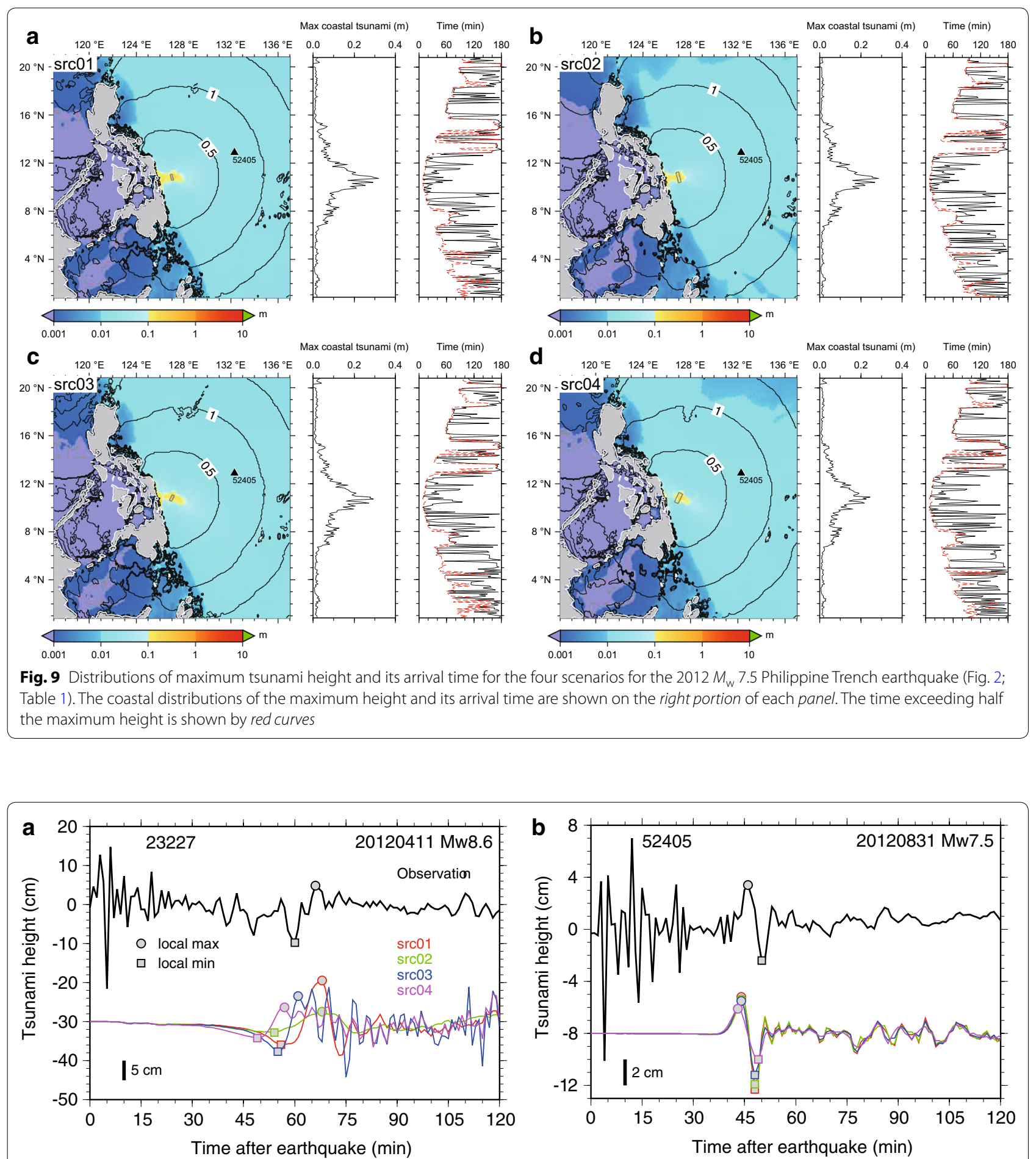

Fig. 10 Tsunami waveforms of the DART observations and the forecasts of the four scenarios. a Shows the results for station 23,227 for the 2012 $M_{w}$ 8.6 off Sumatra event, and $\mathbf{b}$ shows the results for station 52,405 for the $2012 M_{w} 7.5$ Philippine Trench event (Fig. 2)

We evaluated the forecast accuracy of the SWIFT TSUNAMI system for the eight tsunamis $\left(M_{\mathrm{w}} 7.5-8.6\right)$. The system considers forecast uncertainties due to the fault plane selection and the scaling law used and shows four possible scenarios for each tsunamigenic event. The forecast results based on the four scenarios were evaluated by the DART and tide gauge observations. We have shown that the forecasts with associated uncertainties 

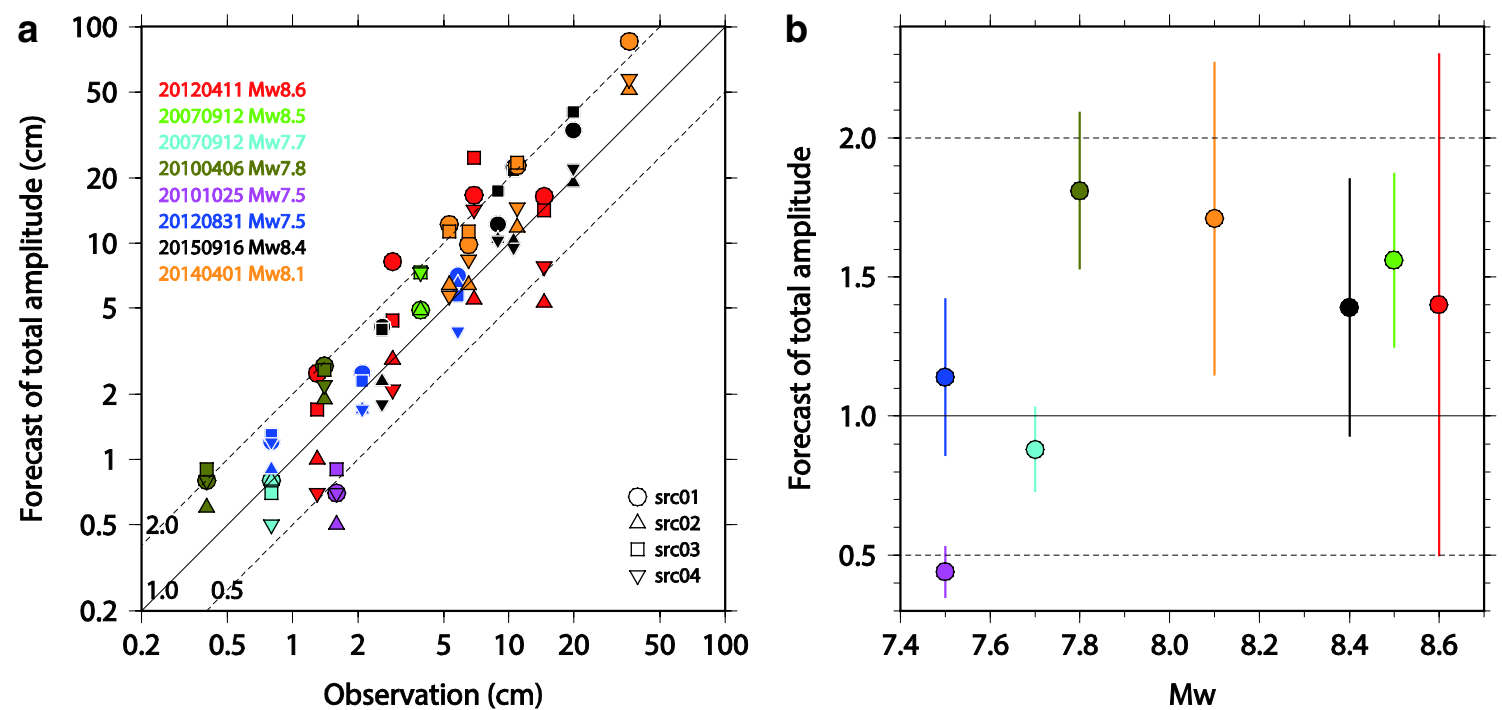

Fig. 11 Summary of forecast accuracy for the eight tsunami events, in terms of the total amplitude of the leading wave of the DART observations. a Shows the observations and forecasts of the four scenarios. b Shows the relationship between $M_{w}$ and normalized average/standard deviation (circle/bar) of the forecasts for each event. The total amplitude is defined as the local maximum minus the local minimum of the leading wave (Fig. 10). The data used in the figure are listed in Table 1
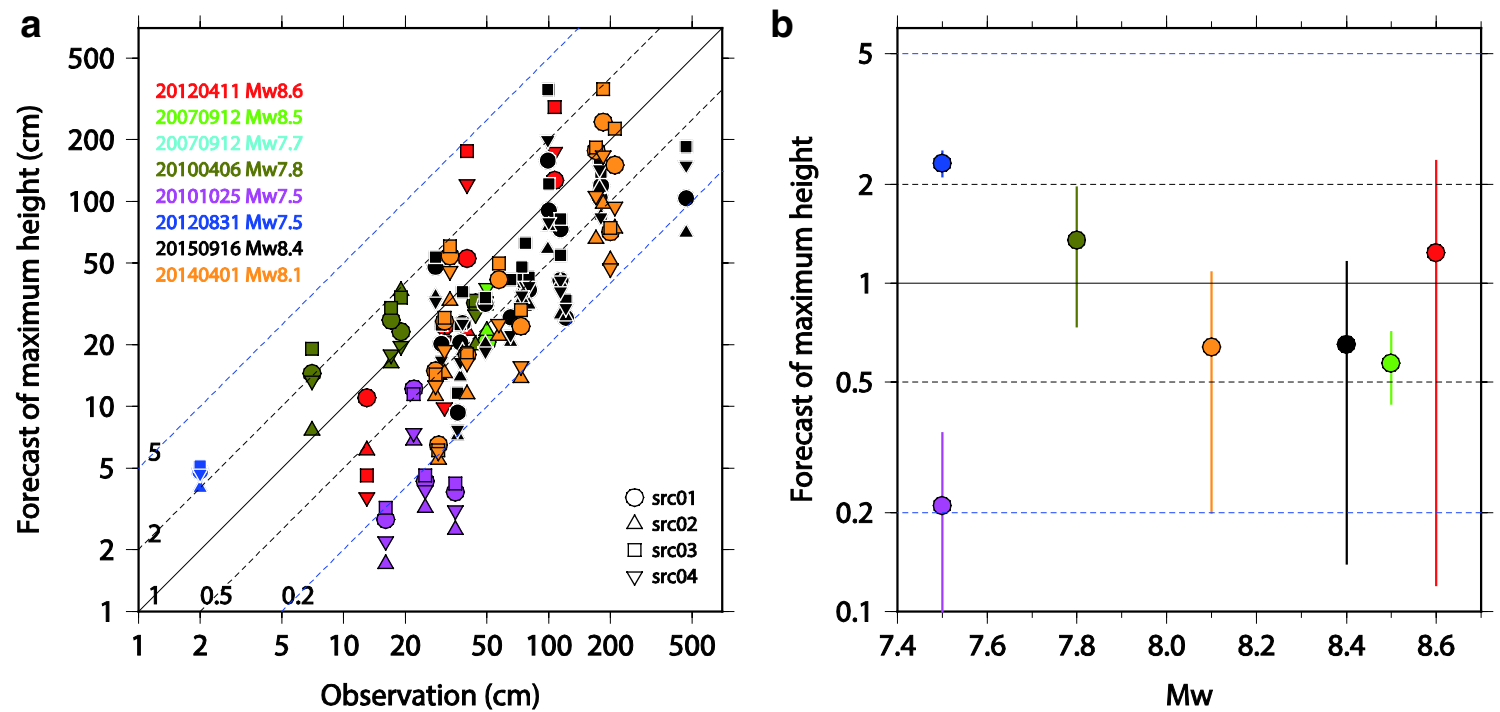

Fig. 12 Same as Fig. 11 but in terms of the maximum height of the coastal tide gauge observations (Figs. 8, 9). Note that we obtained no tide gauge data for the 2007-09-12 $M_{w} 7.7$ tsunami (Table 1)

range from half to double the total amplitude of the leading wave of the DART observations and range mostly within the same order of magnitude as the maximum heights of the tide gauge observations. It is also found that the forecast uncertainties become larger for greater earthquakes because the tsunami source is no longer approximated as a point source for greater earthquakes (e.g., $M_{\mathrm{w}}>8$ ).
We have discussed the practical applicability of the forecast results as well as the forecast accuracy and uncertainties. Users should judge whether the estimated results can be used for forecasting at the target regions and remember the additional forecast uncertainties for greater earthquakes with associated landslides and tsunami earthquakes. Even if the forecast results cannot be used for forecasting, the results will be useful for 


\section{post-disaster activities and for enabling researchers to quickly clarify behaviors of the tsunami.}

\section{Authors' contributions}

DI developed the tsunami calculation system and wrote the majority of the paper. NP developed the earthquake source estimation algorithm and wrote the relevant sections of the paper. EF, $\mathrm{TS}$, and $\mathrm{HK}$ contributed extensively to the scientific discussion. JS provided technical help to automate the developed system. All authors read and approved the final manuscript.

\section{Author details}

1 UTokyo Ocean Alliance, The University of Tokyo, 7-3-1 Hongo, Bunkyo, Tokyo 113-0033, Japan. ${ }^{2}$ National Research Institute for Earth Science and Disaster Resilience, Tsukuba, Japan. ${ }^{3}$ Graduate School of Environmental Studies, Nagoya University, Nagoya, Japan.

\section{Acknowledgements}

This present study was supported by the NIED project for "Development of Monitoring and Forecasting Technology for Crustal Activity."The observed seismic data were obtained through the cooperative research projects with BMKG and PHIVOLCS and through the public servers of IRIS and GEOFON. The DART observation data were downloaded from the NOAA website (http://www. ndbc.noaa.gov/dart.shtml). The tide gauge data were primarily derived from the catalog of the National Tsunami Warning Center (http://ntwc.arh.noaa. gov/about/). Comments from two anonymous reviewers were very useful for improving the manuscript.

\section{Competing interests}

The authors declare that they have no competing interests.

Received: 27 January 2016 Accepted: 14 April 2016

Published online: 04 May 2016

\section{References}

Amante C, Eakins BW (2009) ETOPO1 1 arc-minute global relief model: Procedures, data sources and analysis. NOAA Tech Memo NESDIS NGDC-24, National Geophysical Data Center, National Oceanic and Atmospheric Administration, Boulder. doi:10.7289/N5C8276M

Baba T, Takahashi N, Kaneda Y (2014) Near-field tsunami amplification factors in the Kii Peninsula, Japan for Dense Oceanfloor Network for Earthquakes and Tsunamis (DONET). Mar Geophys Res 35:319-325. doi:10.1007/ s11001-013-9189-1

Baba T, Takahashi N, Kaneda Y, Ando K, Matsuoka D, Kato T (2015) Parallel implementation of dispersive tsunami wave modeling with a nesting algorithm for the 2011 Tohoku tsunami. Pure Appl Geophys 172:34553472. doi:10.1007/s00024-015-1049-2

Baba T, Ando K, Matsuoka D, Hyodo M, Hori T, Takahashi N, Obayashi R, Imato Y, Kitamura D, Uehara H, Kato T, Saka R (2016) Large-scale, high-speed tsunami prediction for the Great Nankai Trough Earthquake on the K computer. Int J High Perform Comput Appl 30:71-84. doi:10.1177/1094342015584090

Barrientos S (2014) The new seismological observation system in Chile and a real time GPS detection of the displacement associated with a $\mathrm{M}=7.7$ earthquake in Chile. 2014 AGU Fall Meeting, G52A-06, San Francisco, CA

Bird P (2003) An updated digital model of plate boundaries. Geochem Geophys Geosyst 4:1027. doi:10.1029/2001GC000252

Bonita JD, Kumagai H, Nakano M (2015) Regional moment tensor analysis in the Philippines: CMT solutions in 2012-2013. J Disaster Res 10:18-24

Calisto I, Miller Ortega M (2015) Observed and modeled tsunami signals compared by using different rupture models of the April 1, 2014, Iquique earthquake. Nat Hazards 79:397-408. doi:10.1007/s1 1069-015-1848-x

Clément J, Reymond D (2015) New tsunami forecast tools for the French Polynesia tsunami warning system part I: moment tensor, slowness and seismic source inversion. Pure Appl Geophys 172:791-804. doi:10.1007/ s00024-014-0888-6

Duputel Z, Rivera L, Kanamori H, Hayes GP, Hirshorn B, Weinstein S (2011) Realtime W phase inversion during the 2011 off the Pacific coast of Tohoku Earthquake. Earth Planets Space 63:535-539. doi:10.5047/eps.2011.05.032
Duputel Z, Kanamori H, Tsai VC, Rivera L, Meng L, Ampuero JP, Stock JM (2012a) The 2012 Sumatra great earthquake sequence. Earth Planet Sci Lett 351-352:247-257. doi:10.1016/j.epsl.2012.07.017

Duputel Z, Rivera L, Kanamori H, Hayes G (2012b) W phase source inversion for moderate to large earthquakes (1990-2010). Geophys J Int 189:11251147. doi:10.1111/j.1365-246X.2012.05419.x

Eakins BW, Grothe PR (2014) Challenges in building coastal digital elevation models. J Coast Res 30:942-953. doi:10.2112/JCOASTRES-D-13-00192.1

Ekström G, Nettles M, Dziewoński AM (2012) The global CMT project 2004-2010: Centroid-moment tensors for 13,017 earthquakes. Phys Earth Planet Inter 200-201:1-9. doi:10.1016/j.pepi.2012.04.002

Fujii Y, Satake K (2007) Tsunami source of the 2004 Sumatra-Andaman earthquake inferred from tide gauge and satellite data. Bull Seismol Soc Am 97:S192-S207. doi:10.1785/0120050613

Fukuyama E, Dreger DS (2000) Performance test of an automated moment tensor determination system for the future "Tokai" earthquake. Earth Planets Space 52:383-392. doi:10.1186/BF03352250

Gusman AR, Tanioka Y (2014) W Phase inversion and tsunami inundation modeling for tsunami early warning: case study for the 2011 Tohoku event. Pure Appl Geophys 171:1409-1422. doi:10.1007/s00024-013-0680-z

Gusman AR, Tanioka Y, Kobayashi T, Latief H, Pandoe W (2010) Slip distribution of the 2007 Bengkulu earthquake inferred from tsunami waveforms and InSAR data. J Geophys Res Solid Earth 115:B12316. doi:10.1029/2010JB007565

Gusman AR, Murotani S, Satake K, Heidarzadeh M, Gunawan E, Watada S, Schurr B (2015) Fault slip distribution of the 2014 Iquique, Chile, earthquake estimated from ocean-wide tsunami waveforms and GPS data. Geophys Res Lett 42:1053-1060. doi:10.1002/2014GL062604

Hanks TC, Kanamori H (1979) A moment magnitude scale. J Geophys Res Solid Earth 84:2348-2350. doi:10.1029/JB084iB05p02348

Heidarzadeh M, Satake K (2014) The El Salvador and Philippines tsunamis of August 2012: insights from sea level data analysis and numerical modeling. Pure Appl Geophys 171:3437-3455. doi:10.1007/ s00024-014-0790-2

Heidarzadeh M, Murotani S, Satake K, Ishibe T, Gusman AR (2016) Source model of the 16 September 2015 Illapel, Chile, $M_{w} 8.4$ earthquake based on teleseismic and tsunami data. Geophys Res Lett 43:643-650. doi:10.10 02/2015GL067297

Igarashi Y, Ueno T, Nakata K, Hernandez-Grennan VC, Cruz-Salcedo JL, Narag IC, Bautista BC, Koizumi T (2015) Building a tsunami simulation database for the tsunami warning system in the Philippines. J Disaster Res 10:51-58

Inazu D, Saito T (2013) Simulation of distant tsunami propagation with a radial loading deformation effect. Earth Planets Space 65:835-842. doi:10.5047/ eps.2013.03.010

Inazu D, Saito T (2016) Global tsunami simulation using a grid rotation transformation in a latitude-longitude coordinate system. Nat Hazards 80:759-773. doi:10.1007/s11069-015-1995-0

Inoue H, Solidum RU (2015) Enhancement of earthquake and volcano monitoring and effective utilization of disaster mitigation information in the Philippines. J Disast Res 10:5-7

International Tsunami Information Center (ITIC) (2015) Pacific Tsunami Warning System: a half-century of protecting the Pacific, 1965-2015, 1st edn. Inoue Regional Center, National Oceanic and Atmospheric Administration, Honolulu

Jamelot A, Reymond D (2015) New tsunami forecast tools for the French Polynesia tsunami warning system Part II: numerical modelling and tsunami height estimation. Pure Appl Geophys 172:805-819. doi:10.1007/ s00024-014-0997-2

Kamigaichi O (2009) Tsunami forecasting and warning. In: Meyers RA (ed) Complexity and systems science. Springer, New York, pp 9592-9618. doi:10.1007/978-0-387-30440-3 568

Kawai H, Satoh M, Kawaguchi K, Seki K (2013) Characteristics of the 2011 Tohoku tsunami waveform acquired around Japan by NOWPHAS equipment. Coast Eng J 55:1350008. doi:10.1142/S0578563413500083

Kawamura K, Laberg JS, Kanamatsu T (2014) Potential tsunamigenic submarine landslides in active margins. Mar Geol 356:44-49. doi:10.1016/j. margeo.2014.03.007

Lauterjung J, Münch U, Rudloff A (2010) The challenge of installing a tsunami early warning system in the vicinity of the Sunda Arc, Indonesia. Nat Hazards Earth Syst Sci 10:641-646. doi:10.5194/nhess-10-641-2010

Maeda T, Obara K, Shinohara M, Kanazawa T, Uehira K (2015) Successive estimation of a tsunami wavefield without earthquake source data: a data 
assimilation approach toward real-time tsunami forecasting. Geophys Res Lett 42:7923-7932. doi:10.1002/2015GL065588

Melgar D, Bock Y (2013) Near-field tsunami models with rapid earthquake source inversions from land- and ocean-based observations: the potential for forecast and warning. J Geophys Res Solid Earth 118:5939-5955. doi:10.1002/2013JB010506

Melgar D, Crowell BW, Bock Y, Haase JS (2013) Rapid modeling of the 2011 $M_{w} 9.0$ Tohoku-oki earthquake with seismogeodesy. Geophys Res Lett 40:2963-2968. doi:10.1002/grl.50590

Miyakawa K, Yamashina T, Inoue H, Ishida M, Masturyono Harjadi P, Kumagai H, Nakano M (2007) Deployment of satellite telemetered broadband seismic network in Indonesia. Tech Note Natl Res Inst Earth Sci Disast Prev 304:25-40 (in Japanese with English abstract)

Miyoshi T, Saito T, Inazu D, Tanaka S (2015) Tsunami modeling from the seismic CMT solution considering the dispersive effect: a case of the 2013 Santa Cruz Islands tsunami. Earth Planets Space 67:4. doi:10.1186/ s40623-014-0179-6

Mungov G, Eblé M, Bouchard R (2013) DART tsunameter retrospective and real-time data: a reflection on 10 years of processing in support of tsunami research and operations. Pure Appl Geophys 170:1369-1384. doi:10.1007/s00024-012-0477-5

Murotani S, Satake K, Fujii Y (2013) Scaling relations of seismic moment, rupture area, average slip, and asperity size for $\mathrm{M} \sim 9$ subduction-zone earthquakes. Geophys Res Lett 40:5070-5074. doi:10.1002/grl.50976

Musa A, Matsuoka H, Watanabe O, Murashima Y, Koshimura S, Hino R, Ohta Y, Kobayashi H (2015) A real-time tsunami inundation forecast system for tsunami disaster prevention and mitigation. The International Conference on High Performance Computing, Networking, Storage and Analysis 2015 (SC15), Technical Program Posters, 91

Nakano M, Kumagai H, Inoue H (2008) Waveform inversion in the frequency domain for the simultaneous determination of earthquake source mechanism and moment function. Geophys J Int 173:1000-1011. doi:10.1111/j.1365-246X.2008.03783.x

Nakano M, Yamashina T, Kumagai H, Inoue H, Sunarjo (2010) Centroid moment tensor catalogue for Indonesia. Phys Earth Planet Inter 183:456-467. doi:10.1016/j.pepi.2010.10.010

Ohtaki T, Kanjo K, Kaneshima S, Nishimura T, Ishihara Y, Yoshida Y, Harada S, Kamiya S, Sunarjo (2000) Broadband seismic network in Indonesia_JISNET. Bull Geol Surv Japan 51:189-203 (in Japanese with English abstract)

Oishi Y, Imamura F, Sugawara D (2015) Near-field tsunami inundation forecast using the parallel TUNAMI-N2 model: application to the 2011 TohokuOki earthquake combined with source inversions. Geophys Res Lett 42:1083-1091. doi:10.1002/2014GL062577

Okada Y (1985) Surface deformation due to shear and tensile faults in a halfspace. Bull Seismol Soc Am 75:1135-1154

Okada Y, Kasahara K, Hori S, Obara K, Sekiguchi S, Fujiwara H, Yamamoto A (2004) Recent progress of seismic observation networks in JapanHi-net, F-net, K-NET and KiK-net-. Earth Planets Space 56:15-28. doi:10.1186/BF03353076

Oleskevich DA, Hyndman RD, Wang K (1999) The updip and downdip limits to great subduction earthquakes: thermal and structural models of Cascadia, south Alaska, SW Japan, and Chile. J Geophys Res Solid Earth 104:14965-14991. doi:10.1029/1999JB900060

Olivieri M, Clinton J (2012) An almost fair comparison between Earthworm and SeisComp3. Seismol Res Lett 83:720-727. doi:10.1785/0220110111

Ozaki T (2011) Outline of the 2011 off the Pacific coast of Tohoku Earthquake ( $M_{w}$ 9.0)-Tsunami warnings/advisories and observations-. Earth Planets Space 63:827-830. doi:10.5047/eps.2011.06.029

Ozaki T (2012) JMA's tsunami warning for the 2011 great Tohoku earthquake and tsunami warning improvement plan. J Disast Res 7:439-445

Pacific Tsunami Warning Center/International Tsunami Information Center (PTWC/ITIC) (2014) Users guide for the Pacific Tsunami Warning Center enhanced products for the Pacific Tsunami Warning System, revised edn. IOC Technical Series 105, UNESCO/IOC, Paris, France

Punongbayan BJT, Kumagai H, Pulido N, Bonita JD, Nakano M, Yamashina T, Maeda Y, Inoue H, Melosantos AA, Figueroa MF, Alcones PCM, Soriano KVC Narag IC, Solidum RU (2015) Development and operation of a regional moment tensor analysis system in the Philippines: contributions to the understanding of recent damaging earthquakes. J Disast Res 10:25-34

Rabinovich AB, Eblé M (2015) Deep-ocean measurements of tsunami waves. Pure Appl Geophys 172:3281-3312. doi:10.1007/s00024-015-1058-1
Reymond D, Okal EA, Hébert H, Bourdet M (2012) Rapid forecast of tsunami wave heights from a database of pre-computed simulations, and application during the 2011 Tohoku tsunami in French Polynesia. Geophys Res Lett 39:L11603. doi:10.1029/2012GL051640

Saito T (2013) Dynamic tsunami generation due to sea-bottom deformation: analytical representation based on the linear potential theory. Earth Planets Space 65:1411-1423. doi:10.5047/eps.2013.07.004

Saito T, Furumura T (2009) Three-dimensional tsunami generation simulation due to sea-bottom deformation and its interpretation based on the linear theory. Geophys J Int 178:877-888. doi:10.1111/j.1365-246X.2009.04206.x

Saito T, Inazu D, Miyoshi T, Hino R (2014) Dispersion and nonlinear effects in the 2011 Tohoku-Oki earthquake tsunami. J Geophys Res Oceans 119:5160-5180. doi:10.1002/2014JC009971

Satake K (2014) Advances in earthquake and tsunami sciences and disaster risk reduction since the 2004 Indian ocean tsunami. Geosci Lett 1:15. doi:10.1186/s40562-014-0015-7

Satake K, Nishimura Y, Putra PS, Gusman AR, Sunendar H, Fujii Y, Tanioka Y, Latief H, Yulianto E (2013) Tsunami source of the 2010 Mentawai, Indonesia earthquake inferred from tsunami field survey and waveform modeling. Pure appl Geophys 170:1567-1582. doi:10.1007/s00024-012-0536-y

Shearer PM (2009) Introduction to seismology, 2nd edn. Cambridge University Press, Cambridge

Tang L, Titov VV, Chamberlin CD (2009) Development, testing, and applications of site-specific tsunami inundation models for real-time forecasting. J Geophys Res Ocean 114:C12025. doi:10.1029/2009JC005476

Tang L, Titov WV, Bernard EN, Wei Y, Chamberlin CD, Newman JC, Mofjeld HO, Arcas D, Eble MC, Moore C, Uslu B, Pells C, Spillane M, Wright L, Gica E (2012) Direct energy estimation of the 2011 Japan tsunami using deepocean pressure measurements. J Geophys Res Oceans 117:C08008. doi:1 $0.1029 / 2011 \mathrm{JC} 007635$

Tanioka Y, Satake K (1996) Tsunami generation by horizontal displacement of ocean bottom. Geophys Res Lett 23:861-864. doi:10.1029/96GL00736

Tanioka Y, Seno T (2001) Sediment effect on tsunami generation of the 1896 Sanriku tsunami earthquake. Geophys Res Lett 28:3389-3392. doi:10.102 9/2001GL013149

Tatehata H (1997) The new tsunami warning system of the Japan Meteorological Agency. In: Hebenstreit G (ed) Perspectives on Tsunami Hazard Reduction. Springer, Netherlands, pp 175-188. doi:10.1007/978-94-015-8859-1_12

Tsushima H, Ohta Y (2014) Review on near-field tsunami forecasting from offshore tsunami data and onshore GNSS data for tsunami early warning. J Disast Res 9:339-357

Tsushima H, Hino R, Fujimoto H, Tanioka Y, Imamura F (2009) Near-field tsunami forecasting from cabled ocean bottom pressure data. J Geophys Res Solid Earth 114:B06309. doi:10.1029/2008JB005988

Tsushima H, Hirata K, Hayashi Y, Tanioka Y, Kimura K, Sakai S, Shinohara M, Kanazawa T, Hino R, Maeda K (2011) Near-field tsunami forecasting using offshore tsunami data from the 2011 off the Pacific coast of Tohoku Earthquake. Earth Planets Space 63:821-826. doi:10.5047/eps.2011.06.052

Tsushima H, Hino R, Tanioka Y, Imamura F, Fujimoto H (2012) Tsunami waveform inversion incorporating permanent seafloor deformation and its application to tsunami forecasting. J Geophys Res Solid Earth 117:B03311. doi:10.1029/2011JB008877

Tsushima H, Hino R, Ohta Y, linuma T, Miura S (2014) tFISH/RAPiD: rapid improvement of near-field tsunami forecasting based on offshore tsunami data by incorporating onshore GNSS data. Geophys Res Lett 41:3390-3397. doi:10.1002/2014GL059863

Utsu T (2001) Seismology, 3rd edn. Kyoritsu Shuppan Co Ltd, Tokyo (in Japanese)

Wang D, Becker NC, Walsh D, Fryer GJ, Weinstein SA, McCreery CS, Sardiña V, Hsu V, Hirshorn BF, Hayes GP, Duputel Z, Rivera L, Kanamori H, Koyanagi KK, Shiro B (2012) Real-time forecasting of the April 11, 2012 Sumatra tsunami. Geophys Res Lett 39:L19601. doi:10.1029/2012GL053081

Watts P, Grilli S, Tappin D, Fryer G (2005) Tsunami generation by submarine mass failure. II: predictive equations and case studies. J Waterway Port Coastal Ocean Eng 131:298-310. doi:10.1061/ (ASCE)0733-950X(2005)131:6(298)

Weatherall P, Marks KM, Jakobsson M, Schmitt T, Tani S, Arndt JE, Rovere M, Chayes D, Ferrini V, Wigley R (2015) A new digital bathymetric model of the world's oceans. Earth Space Sci 2:331-345. doi:10.1002/201 5EA000107 
Wei Y, Chamberlin C, Titor W, Tang L, Bernard EN (2013) Modeling of the 2011 Japan tsunami: lessons for near-field forecast. Pure Appl Geophys 170:1309-1331. doi:10.1007/s00024-012-0519-z

Ye L, Lay T, Kanamori H (2012) Intraplate and interplate faulting interactions during the August 31, 2012, Philippine Trench earthquake $\left(M_{w} 7.6\right)$ sequence. Geophys Res Lett 39:L24310. doi:10.1029/2012GL054164
Yue H, Lay T, Rivera L, Bai Y, Yamazaki Y, Cheung KF, Hill EM, Sieh K, Kongko W, Muhari A (2014) Rupture process of the $2010 M_{w} 7.8$ Mentawai tsunami earthquake from joint inversion of near-field hr-GPS and teleseismic body wave recordings constrained by tsunami observations. J Geophys Res Solid Earth 119:5574-5593. doi:10.1002/2014JB011082

\section{Submit your manuscript to a SpringerOpen ${ }^{\odot}$ journal and benefit from:}

- Convenient online submission

- Rigorous peer review

- Immediate publication on acceptance

- Open access: articles freely available online

- High visibility within the field

- Retaining the copyright to your article 